First publ. in: Limnology and Oceanography / Methods, 1 (2003), pp. 51-62

\title{
Analysis of dissolved noble gases in the porewater of lacustrine sediments
}

\author{
Matthias S. Brennwald ${ }^{1,2}$, Markus Hofer', Frank Peeters 3 , Werner Aeschbach-Hertig ${ }^{4}$, Kuno Strassmann', \\ Rolf Kipfer',5, Dieter M. Imboden² \\ ${ }^{1}$ Environmental Isotopes Group, Water Resources Department, Swiss Federal Institute of Environmental Science and \\ Technology (EAWAG), CH-8600 Dübendorf, Switzerland \\ ${ }^{2}$ Department of Environmental Physics, Swiss Federal Institute of Technology (ETH), CH-8092 Zürich, Switzerland \\ ${ }^{3}$ Limnological Institute, University of Konstanz, D-78457 Konstanz, Germany \\ ${ }^{4}$ Institute of Environmental Physics, University of Heidelberg, D-69129 Heidelberg, Germany \\ ${ }^{5}$ Department of Isotope Geology, Swiss Federal Institute of Technology (ETH), CH-8092 Zürich, Switzerland
}

\begin{abstract}
Here we present a new method for the sampling and quantitative extraction of dissolved $\mathrm{He}, \mathrm{Ne}, \mathrm{Ar}, \mathrm{Kr}$, and Xe from lake sediment samples leading to determinations of porewater noble gas concentration profiles and the isotopic ratios ${ }^{3} \mathrm{He} /{ }^{4} \mathrm{He},{ }^{20} \mathrm{Ne} /{ }^{22} \mathrm{Ne}$, and ${ }^{40} \mathrm{Ar} /{ }^{36} \mathrm{Ar}$. Bulk sediment is transferred from a sediment core into standard $\mathrm{Cu}$ sample tubes without exposure to the atmosphere or other gas reservoirs. The noble gases are then extracted from the porewater by degassing the sediment in an evacuated extraction vessel and analyzed following standard mass spectrometric procedures. In tests of the new method using 0.8 to $1.4 \mathrm{~m}$ long sediment cores from two Swiss lakes, analytical uncertainties were only slightly greater than those of standard water samples. The majority of porewater noble gas concentrations and isotopic ratios were found to correspond closely to those measured in the overlying lake water. Because these values reflect water temperature and salinity during atmospheric equilibration at the lake surface, historical conditions are expected to be archived further downcore in the sediment porewater. This method therefore has great potential for paleolimnological reconstructions. The formation of methane bubbles in anoxic sediment layers is one process that may alter gas distributions. However because the lighter noble gases are most sensitive to degassing effects, noble gas data can be used to detect this process. In addition, noble gas data can yield information on the transport processes occurring in the sediment pore space and on the input of water or gas to the sediment from external sources.
\end{abstract}

\section{Introduction}

Atmospheric noble gases dissolved in lake water can be viewed as proxies for the temperature, salinity, and atmospheric pressure prevailing during their equilibration at the lake surface. This is because in situ noble gas concentrations in a given water parcel in a lake correspond closely to the atmospheric equilibrium concentrations computed from the water temperature, salinity, and atmospheric pressure at the time when the water parcel was last in contact with the atmosphere (Aeschbach-Hertig et al. 1999; Peeters et al. 2000). Thus, the distribution of noble gases in a lake is related to internal mixing conditions, which in turn depend on

\section{Acknowledgments}

We thank D. M. Livingstone (EAWAG) and two anonymous reviewers for their helpful comments and editing assistance. This work was funded by the Swiss Science Foundation (SNF 2000-061498.00 and 2068191.02). the prevailing meteorological conditions. For a recent review of the atmospheric noble gas tracer methodology in aquatic systems, see Stute and Schlosser (2000) and Kipfer et al. (2002).

The noble gas concentrations just above the sediment/ water interface can be expected to be archived in the lake sediment, because during sedimentation part of the overlying water is incorporated into the sediment and is stored in its pore space. The noble gases dissolved in sediment porewater might therefore provide an archive that could be used to reconstruct past noble gas concentrations in lake water on time-scales of up to several thousand years. Such a noble gas archive thus has the potential to provide information on past lake water temperatures and salinities, and hence also on lake level fluctuations. Additionally, the noble gas record in the sediment can be used to quantify and model the in situ transport of dissolved gases within the sediment pore space and to assess the possible input of water or gas from external sources such as groundwater or gas reservoirs below the sediment. 
Until now, only a few published studies have explored dissolved noble gases in lake sediment porewaters. The aim of these studies was to characterize the transport processes in the sediment pore space; hence these studies focused on the light noble gases, which are influenced only weakly by variations in temperature and salinity because their solubilities do not depend strongly on these variables.

Peeper methods have been used to sample dissolved He (Stephenson et al. 1994), but these methods have several disadvantages. Peepers need to be left at the sampling site for He equilibration with the surrounding porewater for several days or weeks (Dyck and Da Silva 1981). Because of their lower diffusivity, the heavier noble gases would require even longer equilibration times. Also, the peeper used by Stephenson et al. (1994) is not suitable for sampling at water depths exceeding $55 \mathrm{~m}$ because the membranes of the gas-filled peeper chambers collapse under the hydrostatic pressure exerted. Furthermore, peeper methods seem to be inappropriate to quantitatively capture poorly soluble species, as indicated by comparing $\mathrm{CH}_{4}$ concentrations obtained from peepers and squeezing techniques (B. Wehrli pers. comm. unref.).

Alternatively, an in situ sampler (Barnes 1973) has been applied in the analysis of dissolved $\mathrm{He}, \mathrm{Ne}, \mathrm{Ar}$, and $\mathrm{Kr}$ in marine sediments to estimate the He flux through the sediment/water interface (Barnes and Bieri 1976). This nonstandard equipment is complicated to operate, and gas leakage may occur from the samples. Torres et al. (1995) and Winckler (1998) determined $\mathrm{He}, \mathrm{Ne}, \mathrm{Ar}, \mathrm{Kr}$, and Xe concentrations using a "WSTP tool" (Barnes 1979, 1988), an enhanced version of the above in situ sampler. It appears that gas bubbles may form in the system during sampling. Hence, exchange of the dissolved sample gases with the gas bubbles affects the noble gas concentrations in the sample in an uncontrollable manner. Also, contamination with the drilling fluid or the water used to fill the WSTP tool may occur (Winckler 1998).

To overcome the shortcomings of the previous methods, we developed a new experimental method for the sampling and extraction of dissolved noble gases in sediment porewater. Lake sediment porewater concentrations of $\mathrm{Ne}, \mathrm{Ar}, \mathrm{Kr}, \mathrm{Xe}$, and in some cases He, can be measured with an accuracy comparable to that attained in the analysis of noble gases in lake water and groundwater. The sampling procedures described here allow the noble gas samples to be prepared rapidly in the field. Both sampling and analysis are routine processes based on standard equipment used in sedimentology and for the analysis of noble gases in water samples.

\section{Materials and procedures}

Sediment sampling for noble gas analysis-Our method for extracting noble gases was designed for sediment cores collected in transparent plastic tubes of $62 \mathrm{~mm}$ outer diameter and $1.5 \mathrm{~mm}$ liner thickness using either a gravity corer or a UWITEC sampling system. The UWITEC system consists of a sediment corer operated from a small floating platform that

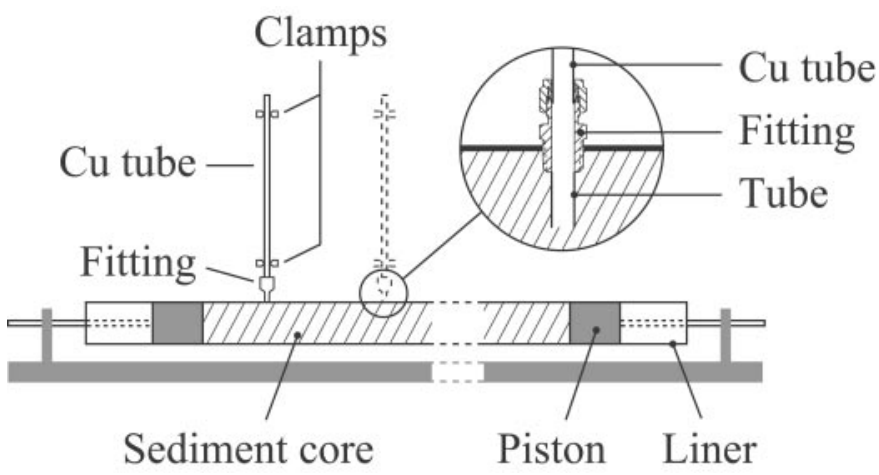

Fig. 1. Sediment squeezer and sampling set-up. The squeezer length can be adjusted for sediment cores with lengths of up to $2 \mathrm{~m}$. Longer cores need to be split up into shorter sections. The $\mathrm{Cu}$ tubes are attached to the liner by means of Swagelock fittings that have been modified with an additional tube to penetrate the sediment core.

allows the iterative collection of overlapping sediment sequences of $3 \mathrm{~m}$ length down to depths of $20 \mathrm{~m}$ or more in the sediment (Melles et al. 1994).

After recovery of the sediment core, about $30 \mathrm{~g}$ of bulk sediment is sampled from the desired sediment depths. Similar to noble gas sampling in water (Kipfer 1991; Beyerle et al. 2000), $\mathrm{Cu}$ tubes of $30 \mathrm{~cm}$ in length and $\approx 1 \mathrm{~cm}$ outer diameter are used as sample containers. The $\mathrm{Cu}$ tubes are connected to the sediment core via Swagelock-fittings (SS-600-1-6BT) that have been modified with an additional tube (length $20 \mathrm{~mm}$, diameter $8 \mathrm{~mm}$ ) to penetrate the sediment core (Fig. 1). These fittings are mounted onto the sediment core by drilling holes $15 \mathrm{~mm}$ in diameter into the plastic liner (sampling ports). Threads are cut into the liner to screw-mount the fittings. To minimize the risk of contaminating the sediment with air during drilling, the sampling ports can be drilled before sediment coring. In this case, the ports are covered by adhesive tape during coring.

The sediment sample is transferred from the sediment liner into the $\mathrm{Cu}$ tubes immediately after collecting the sediment core, using the squeezer setup shown in Fig. 1. The $\mathrm{Cu}$ tubes are flushed with sediment several times to remove residual air and to expel the sediment fraction, which may have exchanged noble gases with the atmosphere while mounting the $\mathrm{Cu}$ tubes. The average sediment displacement observed in the liner due to squeezing is about $2.5 \mathrm{~cm}$ per sample. On this length scale, no significant concentration variations are expected because of diffusion. Hence, consecutively collected samples from the same ports can be treated as replicate samples. The samples are closed and sealed by pinching off the $\mathrm{Cu}$ tubes at both ends using the same standard clamps as those used for water samples (Kipfer 1991; Beyerle et al. 2000). This procedure allows the sampling of intact sediment cores and avoids air contamination and gas stripping during sampling.

Extraction and analysis of dissolved noble gases-The methods used to extract noble gases dissolved in lake water, seawater, or groundwater (Bayer et al. 1989; Beyerle et al. 2000) cannot be 


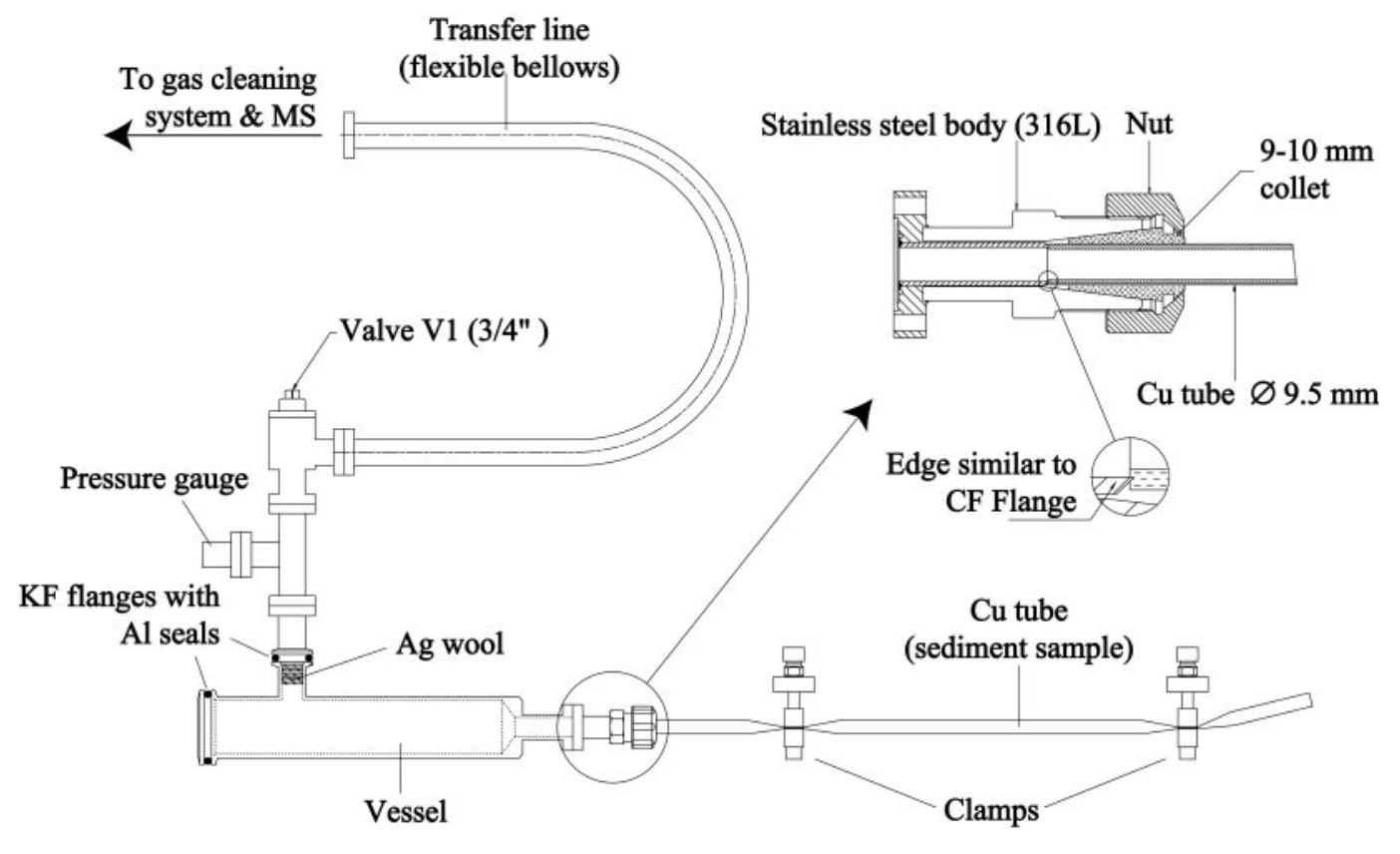

Fig. 2. Noble gas extraction system. During heating of the sample and extraction vessel, valve V1 is closed to ensure that no sediment particles are sprayed into the transfer line. The latter consists of flexible bellows to simplify the mounting of the extraction vessel. The vessel can be removed from the extraction system for sample preparation and cleaning by means of quick release KF flanges (VACOM, types NW16 and NW40) with aluminum seals (VACOM, types NW16 and NW40).

directly applied to extract noble gases from the bulk sediment because the porewater is embedded and trapped in the solid phase of the sediment. The system shown in Fig. 2 was therefore developed to extract the dissolved noble gases from the sediment porewater. The extraction procedure consists of the following steps:

1. The $\mathrm{Cu}$ tube containing the sample is connected to the extraction vessel (length $23 \mathrm{~cm}$, diameter $4 \mathrm{~cm}$ ). The $\mathrm{Cu}$ tube and extraction vessel are weighed for later determination of the amount of water in the sample. The vessel and the headspace of the $\mathrm{Cu}$ tube are evacuated using an ultra-high vacuum pump to a pressure of $10^{-7} \mathrm{mbar}$ or lower. Then the sample is opened by removing the clamp on the vacuum side and reopening the $\mathrm{Cu}$ tube with a pair of pliers as in the case of standard water samples (Kipfer 1991).

2. The $\mathrm{Cu}$ tube, which still contains the sediment sample, is heated using a heating tape to increase the water vapor pressure in the sediment. Once a critical pressure in the $\mathrm{Cu}$ tube has been attained, the sediment is extruded explosively into the extraction vessel (blow-out) where it is evenly spread over the inside walls of the vessel. A wad of silver wool inserted into the outlet of the extraction vessel prevents solid particles from being sprayed out of the extraction vessel and contaminating the rest of the extraction line. It appears that the blowout temperature is specific to the type of sediment. However, even with replicate samples, slightly different temperatures were observed. This is probably due to the variable minimum cross-section of the re-opened $\mathrm{Cu}$ tubes. The blow-out is monitored using a pressure gauge attached to the extraction vessel. The pressure within the extraction vessel can increase up to atmospheric pressure during blow-out, but within seconds it decreases to 70 mbar or less, because the sample gas is cooled by the extraction vessel.

3. After extrusion, the porewater is evaporated by continued heating of the $\mathrm{Cu}$ tube and additional heating of the extraction vessel to release the dissolved noble gases. The large surface area of the sediment deposited in the extraction vessel helps to release the dissolved noble gases quantitatively. The temperature of the $\mathrm{Cu}$ tube is set to $250^{\circ} \mathrm{C}$, whereas the temperature of the extraction vessel is regulated in order not to exceed a maximum pressure of 330 mbar. Otherwise excessive amounts of gases $\left(\mathrm{H}_{2}, \mathrm{CH}_{4}\right)$ may be generated by chemical reactions in the water/sediment mixture, thus impeding the cleaning of the sample gas at a later stage. Thirty minutes after the blow-out, the extraction vessel and $\mathrm{Cu}$ tube are cooled until the pressure in the extraction system falls below 70 mbar.

4. During a period of $10 \mathrm{~min}$, the released sample gases are transferred from the extraction system into the same gas extraction and purification system used for standard water samples (Beyerle et al. 2000). In this system, the condensable gases are trapped at an empty metal trap and a zeolite-filled trap, both cooled by liquid $\mathrm{N}_{2}$. The trapping of the water vapor and other condensable gases generates a gas flow from the extraction vessel into the cold traps. A capillary flow resistance 


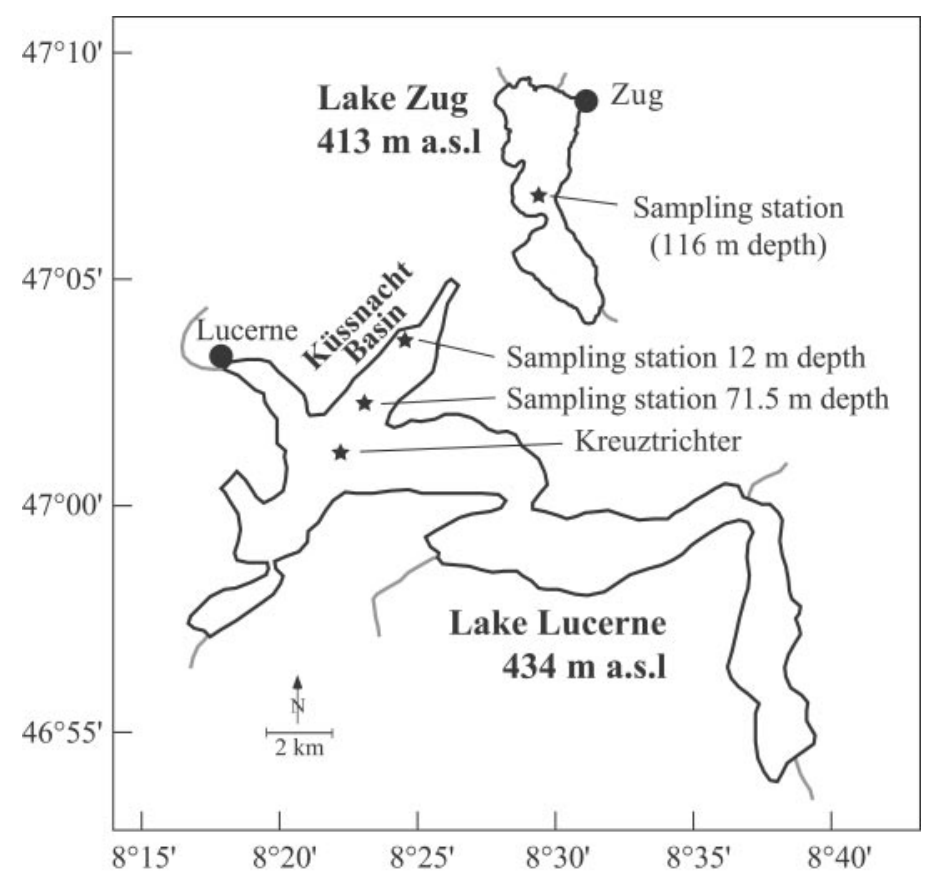

Fig. 3. Sampling sites: Küssnacht Basin (Lake Lucerne) and Lake Zug. From the Küssnacht Basin, one sediment core was taken at $71.5 \mathrm{~m}$ depth $\left(47^{\circ} \mathrm{N} 02.479^{\prime} / 8^{\circ} \mathrm{E} 23.784^{\prime}\right)$ and another at $12 \mathrm{~m}$ depth $\left(47^{\circ} \mathrm{N}\right.$ $\left.03.737^{\prime} / 8^{\circ} \mathrm{E} 24.477^{\prime}\right)$. From Lake Zug, one core was taken at $116 \mathrm{~m}$ depth $\left(47^{\circ} \mathrm{N} 07.866^{\prime} / 8^{\circ} \mathrm{E} 29.156^{\prime}\right)$.

between the extraction vessel and the metal trap prevents back-diffusion of the non-condensable gases (such as He and $\mathrm{Ne}$ ) from the gas purification system into the extraction vessel.

A second extraction cycle comprising steps 3 and 4 is carried out to extract possible gas residues that might have remained in the sediment sample during the first extraction cycle. The total amount of dissolved noble gases in the sample is then given by the sum of the amounts of gas extracted during the first and second extraction cycles.

The mass of porewater in the sediment sample is determined by vacuum-drying the $\mathrm{Cu}$ tube and extraction vessel at $250^{\circ} \mathrm{C}$. The mass of the porewater is then given by the difference of the combined mass of the $\mathrm{Cu}$ tube and the extraction vessel before gas extraction and after drying. In turn, the mass of the solid phase is given by the difference of the sample mass before extraction and the mass of the porewater.

The extracted noble gases are analyzed using the standard method developed for water samples (Beyerle et al. 2000).

\section{Assessment}

Test sites and sediment sampling-The Küssnacht Basin is part of Lake Lucerne, Switzerland (Fig. 3), a freshwater lake situated $434 \mathrm{~m}$ above sea level (a.s.l.). The Küssnacht Basin has a maximum depth of $76 \mathrm{~m}$. The average atmospheric pressure during the years 1960-1990 at the lake surface was 965.7 mbar. During the years 1993-2002, the water temperature at
Kreuztrichter (Fig. 3) ranged from $4.7^{\circ} \mathrm{C}$ to $5.6^{\circ} \mathrm{C}$ at 70 to $75 \mathrm{~m}$ depth, and from $4.8^{\circ} \mathrm{C}$ to $15.5^{\circ} \mathrm{C}$ at 10 to $15 \mathrm{~m}$.

Two sediment cores were collected from the Küssnacht Basin using a gravity corer. The first core (93 cm length) was taken in the deep-water region (71.5-m depth). Noble gas samples were collected at sediment depths of $31 \mathrm{~cm}, 51 \mathrm{~cm}$, and $71 \mathrm{~cm}$. The second core (84-cm length) was taken from a shallow part of the basin (12-m depth) and sampled at sediment depths of $24 \mathrm{~cm}, 44 \mathrm{~cm}$, and $64 \mathrm{~cm}$. The sediment sampling ports were drilled into the liners before coring and were sealed with adhesive tape until the sediment was transferred into the $\mathrm{Cu}$ tubes.

Lake Zug, Switzerland (Fig. 3), is a $197 \mathrm{~m}$ deep meromictic freshwater lake situated at $413 \mathrm{~m}$ a.s.l. The average atmospheric pressure during the years 1960-1990 at the lake surface was 968.2 mbar. Because of the increasing chemical stratification of the deep water body, no full turnover of the water column has occurred since 1950 (Müller 1993), hence the deep water of Lake Zug is anoxic.

The deep-water temperature of the lake (100 to $197 \mathrm{~m}$ ) varies only slightly $\left(\mathrm{SD}=0.14^{\circ} \mathrm{C}\right)$ about a long-term mean of $4.4^{\circ} \mathrm{C}$ (Livingstone 1993). Thus, the noble gas concentrations in the deep water body are expected to remain stable over time. This provides a simple set of boundary conditions for the noble gas concentrations at the sediment/water interface.

A sediment core of $139 \mathrm{~cm}$ in length was recovered from $116 \mathrm{~m}$ water depth in Lake Zug using a gravity corer. The upper $80 \mathrm{~cm}$ of the sediment was of a uniform dark color, indicating anoxic deep-water conditions during the last few decades. In this part of the sediment, small gas bubbles (with an estimated diameter of $1 \mathrm{~mm}$ or less) formed because of the decrease in hydrostatic pressure as the core was raised. This indicates elevated concentrations of dissolved gases in the sediment.

Sediment samples were collected at sediment depths of $15 \mathrm{~cm}, 40 \mathrm{~cm}, 80 \mathrm{~cm}$, and $100 \mathrm{~cm}$. The sampling ports to access the sediment in the liner were drilled after sediment coring.

Extraction efficiency-After extraction and analysis, extraction steps 3 and 4 were repeated for each sample in order to determine the efficiency of the extraction method. For some samples, extraction was conducted at different temperatures. The results show that the extraction efficiency is strongly temperature-dependent. At temperatures below $250^{\circ} \mathrm{C}$, either the critical pressure for blow-out was not reached or the extraction was not complete. In these cases, the quantity of gas extracted in the second extraction cycle exceeded $10 \%$ of the amount extracted in the first cycle. At temperatures above $250^{\circ} \mathrm{C}$, excessive amounts of gases such as $\mathrm{H}_{2}$ or $\mathrm{CH}_{4}$ are formed, which interfere with the cleaning of the sample gas in the purification line and prevent routine operation of the analytical system. In addition, at high temperatures, radiogenic He produced in the minerals may be released from the sediment matrix (see below).

To test whether enough heat was applied to quantitatively extract the dissolved noble gases, one sample from the Küss- 


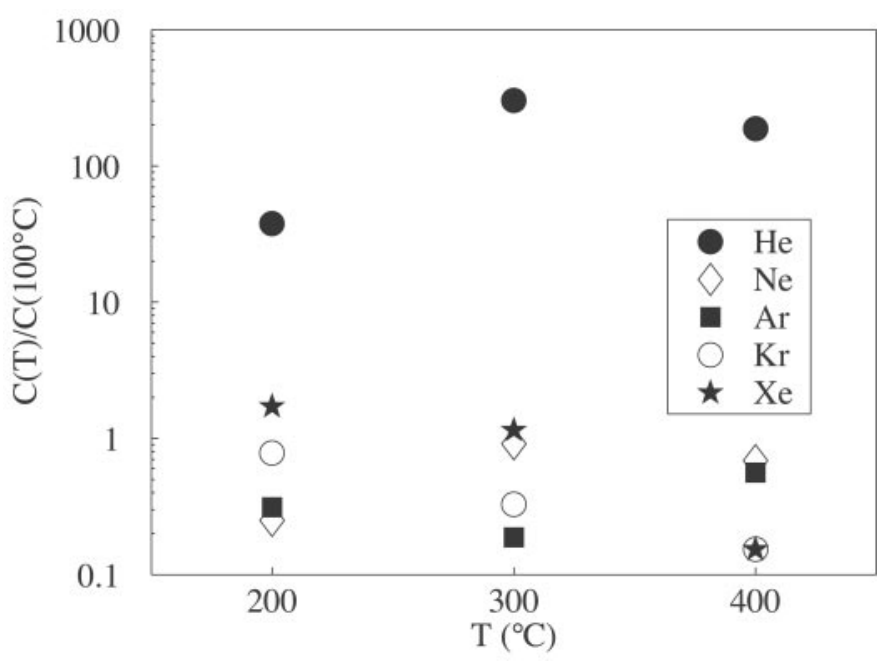

Fig. 4. Noble gas concentrations (standard temperature and pressure [STP] volume per unit mass of dry sediment) observed in the stepwise heating experiment with pre-degassed sediment at temperatures $\mathrm{T}=$ $200^{\circ} \mathrm{C}, 300^{\circ} \mathrm{C}$, and $400^{\circ} \mathrm{C}$. The concentrations were normalized by the values measured in the first extraction cycle at $100^{\circ} \mathrm{C}$ (units $\left.\mathrm{cm}_{\text {STP }}^{3} / \mathrm{g}_{\text {dry mass }}\right): \mathrm{He}=(1.3 \pm 0.2) 10^{-10}, \mathrm{Ne}=(2.4 \pm 0.2) 10^{-10}, \mathrm{Ar}=(1.2 \pm$ $0.7) 10^{-6}, \mathrm{Kr}=(3 \pm 1) 10^{-10}, \mathrm{Xe}=(3 \pm 2) 10^{-11}$. Note that these concentrations are more than 100 times lower than the typical equilibrium concentrations in the water. With the exception of $\mathrm{He}$, the concentrations measured during the subsequent cycles correspond to about $0.1 \%$ of the noble gas concentrations in the pore water.

nacht Basin (K01) was subjected to an additional extraction cycle at $400^{\circ} \mathrm{C}$ after the normal extraction cycles at $250^{\circ} \mathrm{C}$. Except for $\mathrm{He}$, the gas quantities extracted at $400^{\circ} \mathrm{C}$ were close to the blank level of the analytical system and were less than $0.4 \%$ of the gas amount extracted at $250^{\circ} \mathrm{C}$. In contrast, the quantity of He extracted at $400^{\circ} \mathrm{C}$ corresponds to about $8 \%$ of the gas amount extracted at $250^{\circ} \mathrm{C}$. This points to the release of He trapped in the mineral phase of the sediment matrix.

To assess the possible release of noble gases from the sediment minerals, $40.5 \mathrm{~g}$ of wet bulk sediment from the Küssnacht Basin was spread over the inside of the extraction vessel. The sediment was distributed evenly to maximize its surface area and thus facilitate the release of dissolved gases. After evacuation of the extraction vessel, the porewater was left in the vessel overnight without heating the sample. The released gases were then pumped out of the extraction vessel using a rotary pump and a metal cold trap cooled by liquid $\mathrm{N}_{2}$, whereby the attained minimum pressure of 20 mbar (water vapor pressure) was maintained for $5 \mathrm{~min}$. The sample was then heated to $100^{\circ} \mathrm{C}$ for $30 \mathrm{~min}$ and extracted and analyzed as described above. This procedure was repeated at increasing temperatures $\left(200^{\circ} \mathrm{C}, 300^{\circ} \mathrm{C}, 400^{\circ} \mathrm{C}\right)$. In the case of $\mathrm{Ne}, \mathrm{Ar}, \mathrm{Kr}$, and $\mathrm{Xe}$, the gas amounts released were negligible, and no increase was observed with increasing temperature (Fig. 4). In contrast to Ne-Xe, He was indeed found to be released from the mineral phase. The amount of trapped He per unit mass of dry sediment varied from $1.3 \cdot 10^{-10}$ to $3.84 \cdot 10^{-8} \mathrm{~cm}_{\text {STP }}^{3} / g_{\text {dry mass }}$ and increased with increasing temperature. The cumulative amount of He released at temperatures up to $300^{\circ} \mathrm{C}$ corresponds to about $4 \cdot 10^{-8} \mathrm{~cm}^{3}{ }_{\text {STP }} / \mathrm{g}_{\text {dry mass }}$ which is similar to the concentration of dissolved He in the porewater. Because in this study the typical mass ratio of porewater to solid phase is approximately 2:1, the measured He data from the Küssnacht Basin (Table 1) reflect a mixture of predominantly dissolved $\mathrm{He}$ in the porewater and a smaller amount of trapped He released from the mineral phase.

Table 2 summarizes the extraction efficiencies for $\mathrm{He}, \mathrm{Ne}, \mathrm{Ar}$, $\mathrm{Kr}$, and Xe resulting from the standard extraction procedure conducted at $250^{\circ} \mathrm{C}$. We define the extraction efficiency as the ratio of the STP volume of gas obtained in the first extraction cycle to the total STP volume obtained in both cycles. As discussed above, the second extraction cycle yielded significant amounts of He, especially in the case of the Küssnacht Basin. In contrast to He, the mean extraction efficiency for Ne is better than $99 \%$. The extraction efficiencies for the heavier noble gases are similar to that for $\mathrm{Ne}$, with a slight decreasing trend toward the heavier noble gases. The lowest mean extraction efficiency was observed for Xe in Lake Zug (94.3\%).

We chose a degassing temperature of $250^{\circ} \mathrm{C}$ because this temperature yields good extraction efficiencies and the amounts of $\mathrm{CH}_{4}$ and $\mathrm{H}_{2}$ produced during extraction are manageable.

Reproducibility of replicate samples-The reproducibility of the method was evaluated by comparing replicate measurements from the same sampling ports. Seven sets of duplicate measurements and two sets of triplicate measurements were available for this comparison. Each individual measurement was normalized by dividing by the mean value of all replicate measurements from the same sampling port. This removed any possible natural downcore variation from the data. The standard deviations of the normalized data reflect the overall relative uncertainties in the measured concentrations and isotope ratios, including those associated with sampling, gas extraction, and analysis. These standard deviations are listed in Table 1 as "Uncertainties."

The uncertainties in the $\mathrm{Ne}, \mathrm{Ar}, \mathrm{Kr}$, and Xe concentration measurements are about $2 \%$ of the respective mean concentrations, whereas the uncertainties in the ${ }^{20} \mathrm{Ne} /{ }^{22} \mathrm{Ne}$ and ${ }^{40} \mathrm{Ar} /{ }^{36} \mathrm{Ar}$ isotope ratios are $0.06 \%$ and $0.12 \%$, respectively. These uncertainties are only slightly greater than the analytical uncertainty attainable for standard lake and groundwater samples (Beyerle et al. 2000). However, the uncertainties in the He concentration measurements (4\%) and the ${ }^{3} \mathrm{He} /{ }^{4} \mathrm{He}$ isotope ratios (9\%) are significantly greater. This seems to originate from the uncontrolled release of trapped He from the mineral phase, as indicated by the elevated amounts of ${ }^{4} \mathrm{He}$ observed in the second extraction cycle of the Küssnacht Basin samples. In the case of Lake Zug, however, the relative amount of ${ }^{4} \mathrm{He}$ released during the second extraction cycle (Table 2) is similar to that of $\mathrm{Ne}$, and the estimated uncertainty in the He concentration is less than $3 \%$. This suggests that the minerals of the Lake Zug sediment matrix do not release substantial amounts of $\mathrm{He}$ at $250^{\circ} \mathrm{C}$. 
Table 1. Noble gas concentrations and isotope ratios in the pore water of the Lake Zug and Küssnacht Basin sediment at sediment depth $z$

\begin{tabular}{|c|c|c|c|c|c|c|c|c|c|}
\hline Sample & $\begin{array}{c}Z \\
(\mathrm{~cm}) \\
\end{array}$ & $\begin{array}{c}\mathrm{He} \\
\left(10^{-8} \mathrm{~cm}_{\mathrm{ST}}^{3} / \mathrm{g}\right)\end{array}$ & $\begin{array}{c}\mathrm{Ne} \\
\left(10^{-7} \mathrm{~cm}_{\mathrm{spP}}^{3} / \mathrm{g}\right)\end{array}$ & $\begin{array}{c}\mathrm{Ar} \\
\left(10^{-4} \mathrm{~cm}_{\mathrm{STP}}^{3} / \mathrm{g}\right)\end{array}$ & $\begin{array}{c}\mathrm{Kr} \\
\left(10^{-7} \mathrm{~cm}_{\mathrm{ST}}^{3} / \mathrm{g}\right)\end{array}$ & $\begin{array}{c}\mathrm{Xe} \\
\left(10^{-8} \mathrm{~cm}_{\mathrm{STP}}^{3} / \mathrm{g}\right)\end{array}$ & $\begin{array}{c}{ }^{3} \mathrm{He} /{ }^{4} \mathrm{He} \\
\left(10^{-6}\right)\end{array}$ & ${ }^{20} \mathrm{Ne} /{ }^{22} \mathrm{Ne}$ & ${ }^{40} \mathrm{Ar} /{ }^{36} \mathrm{Ar}$ \\
\hline \multicolumn{10}{|c|}{ Lake Zug, $116 \mathrm{~m}$ water depth } \\
\hline$Z e q^{a}$ & & 4.65 & 2.07 & 4.29 & 1.04 & 1.57 & 1.36 & 9.780 & 295.8 \\
\hline Z01 & 15 & 4.7 & 1.92 & 4.13 & 1.02 & 1.51 & 2.82 & 9.783 & 295.6 \\
\hline Z02 & 15 & 5.0 & 1.98 & 4.10 & 0.99 & 1.55 & $-^{\mathrm{b}}$ & 9.777 & 295.0 \\
\hline Z03 & 40 & 4.6 & 1.88 & 4.06 & 0.99 & 1.50 & - & 9.792 & 294.7 \\
\hline Z04 & 40 & - & - & 4.08 & 0.99 & 1.55 & - & - & 296.1 \\
\hline Z05 & 40 & 4.4 & 1.80 & 3.95 & 0.97 & 1.48 & 2.83 & 9.809 & 296.4 \\
\hline Z06 & 80 & 4.9 & 1.91 & 4.15 & 1.00 & 1.56 & 2.78 & 9.784 & 295.8 \\
\hline Z07 & 100 & 5.6 & 2.13 & 4.19 & 0.99 & 1.58 & 2.80 & 9.798 & 295.7 \\
\hline Z08 & 100 & - & - & 4.22 & 1.02 & 1.56 & - & 9.798 & 296.3 \\
\hline Z09 & 100 & 5.8 & 2.26 & 4.39 & 1.05 & 1.57 & 2.88 & 9.809 & 296.6 \\
\hline \multicolumn{10}{|c|}{ Küssnacht Basin, $12 \mathrm{~m}$ water depth } \\
\hline$K W 12 e q^{c}$ & & 4.44 & 1.93 & 3.72 & 0.890 & 1.28 & 1.36 & 9.780 & 295.8 \\
\hline$K W 12 m^{d}$ & & 4.61 & 1.89 & 3.62 & 0.850 & 1.24 & 1.32 & 9.786 & 295.6 \\
\hline K01 & 24 & 4.9 & 1.91 & 3.83 & 0.925 & 1.48 & 1.35 & 9.802 & 295.6 \\
\hline K02 & 24 & 5.3 & 1.83 & 4.07 & 1.01 & 1.63 & 1.36 & 9.788 & 295.7 \\
\hline K03 & 44 & - & - & 3.75 & 0.93 & 1.50 & - & - & 296.2 \\
\hline K04 & 44 & - & - & 4.02 & 0.97 & 1.56 & - & - & 296.1 \\
\hline K05 & 64 & 5.5 & 1.79 & 3.87 & 0.92 & 1.48 & 1.81 & 9.797 & 295.6 \\
\hline K06 & 64 & 5.4 & 1.84 & 3.97 & 0.94 & 1.50 & 1.74 & 9.786 & 295.7 \\
\hline \multicolumn{10}{|c|}{ Küssnacht Basin, $71.5 \mathrm{~m}$ water depth } \\
\hline$K W 71.5 e^{c}$ & & 4.53 & 2.02 & 4.13 & 1.00 & 1.50 & 1.36 & 9.780 & 295.8 \\
\hline$K W 71.5 m^{d}$ & & 4.74 & 2.02 & 4.02 & 0.967 & 1.42 & 1.34 & 9.785 & 295.6 \\
\hline K07 & 31 & 5.3 & 1.81 & 4.12 & 0.991 & 1.71 & 2.23 & 9.798 & 295.1 \\
\hline K08 & 31 & - & - & - & - & 1.68 & - & - & - \\
\hline K09 & 51 & - & - & 4.21 & 1.01 & 1.73 & - & - & 295.9 \\
\hline K10 & 51 & 5.0 & 1.89 & 3.97 & 0.97 & 1.65 & 2.40 & 9.801 & 295.5 \\
\hline K11 & 71 & 6.0 & 1.87 & 4.16 & 1.04 & 1.81 & 1.90 & 9.783 & 296.0 \\
\hline K12 & 71 & 5.2 & 1.90 & 4.02 & 0.99 & 1.67 & 2.65 & 9.786 & 296.0 \\
\hline Uncertainty ${ }^{e}$ & & $4.0 \%$ & $2.1 \%$ & $2.3 \%$ & $2.2 \%$ & $2.5 \%$ & $9.0 \%$ & $0.06 \%$ & $0.13 \%$ \\
\hline
\end{tabular}

a Zeq denotes the atmospheric equilibrium concentrations and isotope ratios of the overlying water in Lake Zug $\left(4.4^{\circ} \mathrm{C}, 968.2 \mathrm{mbar}\right)$.

b_ missing data values are due to experimental loss.

${ }^{c} \mathrm{KW} 12 \mathrm{eq}$ and $\mathrm{KW} 71.5 \mathrm{eq}$ are the atmospheric equilibrium concentrations and isotope ratios of the overlying water in the Küssnacht Basin corresponding to the respective annual mean temperatures $\left(12 \mathrm{m:} 9.5^{\circ} \mathrm{C} ; 71.5 \mathrm{~m}: 5.2^{\circ} \mathrm{C}\right)$ and atmospheric pressure $(965.7 \mathrm{mbar})$.

${ }^{\mathrm{d}} \mathrm{KW} 12 \mathrm{~m}$ and $\mathrm{KW} 71.5 \mathrm{~m}$ are the measured noble gas concentrations (typical uncertainty $1 \%$ ) and isotope ratios (typical uncertainty $0.1 \%$ ) in the overlying water in the Küssnacht Basin at $12 \mathrm{~m}$ and $71.5 \mathrm{~m}$ depth, respectively.

eThe overall uncertainties in the sediment data (bottom of the table) were estimated by comparing replicate samples (see text).

Küssnacht Basin: comparison of deep-water and shallowwater sediment data-The concentrations of the heavy noble gases in the Küssnacht Basin porewater are distinctly higher in the sediment sampled at $71.5 \mathrm{~m}$ water depth than in the sediment sampled at $12 \mathrm{~m}$ water depth (Table 1 ). These concentration differences increase systematically with atomic mass, which reflects the temperature difference between deep and shallow water. Because atmospheric equilibrium concentrations decrease with increasing temperature, the higher noble gas concentrations in the deep-water sediment indicate that the deep water equilibrated at a lower temperature than the shallow water. This is reasonable because the deep water forms during the cold season when the surface temperature is close to $4^{\circ} \mathrm{C}$. Because the solubilities of the heavy noble gases are more sensitive to temperature variations than those of the lighter noble gases, the concentration difference between deep and shallow water is greater for the heavier noble gases.

Table 3 illustrates the noble gas temperatures corresponding to the $\mathrm{Ar}, \mathrm{Kr}$, and Xe concentrations measured in the sediment, i.e., the temperatures that would yield equilibrium concentrations identical to the measured concentrations (Stute and Schlosser 2000; Kipfer et al. 2002). All atmospheric equilibrium concentrations in this study were calculated using the solubility data recommended by Kipfer et al. (2002). At both sampling depths the noble gas temperatures calculated from $\mathrm{Ar}$ and $\mathrm{Kr}$ 
Table 2. Extraction efficiencies, $E$ (\%), for $\mathrm{He}, \mathrm{Ne}, \mathrm{Ar}, \mathrm{Kr}$, and $\mathrm{Xe}$ (minimum, maximum, and mean values of the Küssnacht Basin and Lake Zug sample sets) ${ }^{\mathrm{a}}$

\begin{tabular}{lrrrrr}
\hline & $E(\mathrm{He})$ & $E(\mathrm{Ne})$ & $E(\mathrm{Ar})$ & $E(\mathrm{Kr})$ & $E(\mathrm{Xe})$ \\
\hline $\begin{array}{l}\text { Küssnacht Basin } \\
\quad \text { Minimum }\end{array}$ & 90.4 & 98.6 & 92.3 & 89.6 & 87.6 \\
$\quad$ Maximum & 99.8 & 100.0 & 99.8 & 99.9 & 99.6 \\
$\quad$ Mean & 96.9 & 99.5 & 98.5 & 98.1 & 97.7 \\
Lake Zug & & & & & \\
$\quad$ Minimum & 93.6 & 97.3 & 95.8 & 93.2 & 88.6 \\
$\quad$ Maximum & 99.6 & 100.0 & 99.6 & 100.0 & 99.5 \\
$\quad$ Mean & 98.4 & 99.2 & 97.2 & 96.3 & 94.3 \\
\hline
\end{tabular}

${ }^{a}$ The extraction efficiency is defined as the volume of gas extracted during the first extraction cycle relative to that extracted during both cycles.

are mutually consistent. At $71.5 \mathrm{~m}$ depth, they also agree with the annual mean water temperature at this depth in the Küssnacht Basin, whereas at $12 \mathrm{~m}$ the noble gas temperatures are $2^{\circ} \mathrm{C}$ to $2.5^{\circ} \mathrm{C}$ lower than the local mean water temperature. This discrepancy must be related to the physical processes that determine the water temperature and noble gas concentrations of a given water parcel.

Once a water parcel is isolated from the water surface, its noble gas concentration can only change by mixing, which alters water temperature as well. However, as the atmospheric noble gas equilibrium concentrations are roughly linearly dependent on water temperature, water temperature and gas concentration remain at apparent equilibrium during mixing.

Yet, water temperature in a water parcel below the water surface can also increase because of the local absorption of solar radiation. The water temperature may therefore exceed the noble gas temperature by a small amount, because gas reequilibration with the atmosphere is inhibited. This effect is important primarily in spring and summer when the shallow water is formed because solar radiation is strong and vertical mixing slow. In contrast, in winter, when the deep water is formed, this effect will be small because solar radiation is weak and vertical mixing fast, so that a water parcel will not remain for very long in the top $10 \mathrm{~m}$ of the water column where most of the solar radiation is absorbed.

The temperatures calculated from Xe show a different picture. At both depths, the temperatures are significantly lower than the water temperature. This discrepancy cannot be explained by the above mechanism. Whereas contamination of the noble gas samples cannot be ruled out, it seems unlikely that all samples were contaminated with a similar amount of Xe but not with other noble gases. A more likely explanation for the Xe excess might be adsorption of Xe on to the sediment matrix. Depending on the mineral type and grain size of the sediment, the amount of adsorbed Xe may be significant (Podosek et al. 1981; Tolstikhin and O'Nions 1994) and might be eluded during heating and extraction. Because $\mathrm{He}-\mathrm{Kr}$ are known to adsorb less on to mineral surfaces than Xe, no
Table 3. Noble gas temperatures corresponding to the average $\mathrm{Ar}, \mathrm{Kr}$, and $\mathrm{Xe}$ concentrations measured in the sediment of the Küssnacht Basin at $12 \mathrm{~m}$ and $71.5 \mathrm{~m}$ depth $\left(\mathrm{T}_{\mathrm{Ar}}, \mathrm{T}_{\mathrm{Kr}}, \mathrm{T}_{\mathrm{Xe}}\right)$, and the mean, minimum, and maximum values of the instrumental water temperature record in Kreuztrichter from 1998 to 2002 at the same depths $\left(T_{\text {mean }}, T_{\text {min }}, T_{\text {max }}\right)$, in ${ }^{\circ} \mathrm{C}^{a}$

\begin{tabular}{lcccccc}
\hline & $\mathrm{T}_{\mathrm{Ar}}$ & $\mathrm{T}_{\mathrm{Kr}}$ & $\mathrm{T}_{\text {Xe }}$ & $\mathrm{T}_{\text {mean }}$ & $\mathrm{T}_{\text {min }}$ & $\mathrm{T}_{\text {max }}$ \\
\hline $12 \mathrm{~m}$ & $7.4 \pm 1.3$ & $6.9 \pm 0.4$ & $4.7 \pm 1.1$ & 9.5 & 4.8 & 14.3 \\
$71.5 \mathrm{~m}$ & $5.6 \pm 0.9$ & $5.4 \pm 0.7$ & $2.7 \pm 1.9$ & 5.2 & 4.7 & 5.6 \\
\hline
\end{tabular}

${ }^{a}$ The uncertainties in the noble gas temperatures correspond to the standard deviations of the measured noble gas concentrations.

observable excess would be expected for these noble gases. However to the authors' knowledge, sorption of Xe on natural minerals in aqueous systems has not been systematically examined. The underlying processes generating the observed Xe excess therefore remain unknown.

The average concentrations of $\mathrm{Ar}, \mathrm{Kr}$, and $\mathrm{Xe}$ in the porewater are slightly higher than those measured in the water overlying the sediment/water interface (Table 1). The overlying water samples were collected in autumn, so their temperatures will tend to exceed the annual mean temperature. Because the porewater concentrations are expected to reflect long-term mean noble gas concentrations in the overlying water, the observed concentrations in the overlying water may be lower than in the porewater. Also, the $\mathrm{Ar}$ and $\mathrm{Kr}$ discrepancies between overlying and porewater are greater at $12 \mathrm{~m}$ than at $71.5 \mathrm{~m}$ water depth, which is presumably a result of the higher variability of the water temperature at $12 \mathrm{~m}$. For Xe, this effect may be masked by the Xe excess.

In the case of the lighter noble gases ${ }^{4} \mathrm{He}$ and $\mathrm{Ne}$, no clear systematic difference between $12 \mathrm{~m}$ and $71.5 \mathrm{~m}$ water depth is observed (Fig. 5), because their solubilities are less sensitive to temperature variations. The Ne concentrations in the porewater seem to be approximately $6 \%$ lower than the equilibrium concentrations corresponding to the temperatures indicated by $\mathrm{Ar}$ and $\mathrm{Kr}$ (Fig. 5). Also, the Ne concentrations in the sediment are lower than the measured concentrations in the overlying water by a similar amount (Table 1 ). This may point to a slight degassing effect, which will be discussed in the next section.

In contrast to ${ }^{4} \mathrm{He}$ and $\mathrm{Ne}$, the ${ }^{3} \mathrm{He}$ concentrations at $12 \mathrm{~m}$ water depth are significantly lower than at $71.5 \mathrm{~m}$ water depth. Both ${ }^{3} \mathrm{He}$ and ${ }^{4} \mathrm{He}$ are supersaturated with respect to their atmospheric equilibrium concentrations. In the case of ${ }^{3} \mathrm{He}$, this is due to the production of tritiogenic ${ }^{3} \mathrm{He}$ by the radioactive decay of ${ }^{3} \mathrm{H}$. Radiogenic ${ }^{4} \mathrm{He}$ produced in the sediment matrix by the decay of $U$ and $T h$ is likely to enter the porewater in situ and may be released during noble gas extraction. Also, terrigenic ${ }^{4} \mathrm{He}$ originating from below the lake sediment may be transported upwards into the sediment. Hence, an increase of ${ }^{4} \mathrm{He}$ with sediment depth would be expected (Barnes and Bieri 1976). Despite the large degree of scatter, the ${ }^{4} \mathrm{He}$ data shown in Fig. 5 are consistent with such a vertical He gradient. 

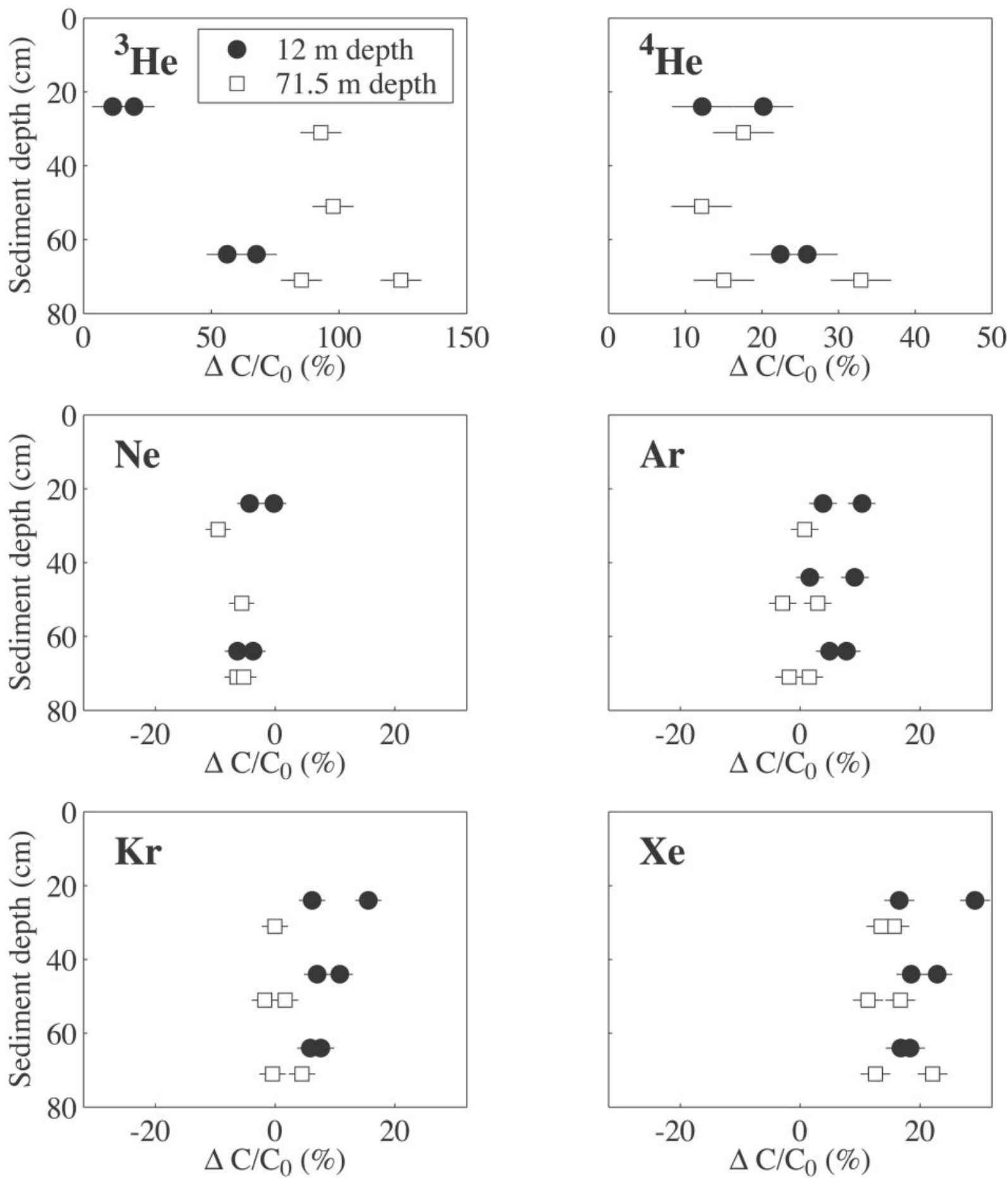

Fig. 5. Normalized noble gas concentrations in the pore water of the Küssnacht Basin versus sediment depth. $\Delta C$ is the difference of the measured concentration and the equilibrium concentration $C_{0}$ corresponding to the atmospheric pressure at the lake surface and the annual mean water temperatures at $12 \mathrm{~m}$ and $71.5 \mathrm{~m}$ depth, respectively, $C_{0}(12 \mathrm{~m})<C_{0}(71.5 \mathrm{~m})$ (Table 1$)$. The error bars reflect the overall analytical uncertainties (see text and Table 1$)$. Note the different scaling of the concentration axes for the He isotopes. 
Table 4. Degassing and air contamination models for Lake Zug sediment data

\begin{tabular}{|c|c|c|c|c|c|c|}
\hline Sample & $\begin{array}{c}Z^{\mathrm{a}} \\
(\mathrm{cm})\end{array}$ & Model $^{b}$ & $\begin{array}{c}B^{\mathrm{C}} \\
\left(10^{-3} \mathrm{~cm}_{\mathrm{STP}}^{3} / \mathrm{g}\right)\end{array}$ & $\begin{array}{c}\Delta \mathrm{B}^{\mathrm{c}} \\
\left(10^{-3} \mathrm{~cm}_{\mathrm{STP}}^{3} / \mathrm{g}\right)\end{array}$ & $\begin{array}{c}A^{\mathrm{C}} \\
\left(10^{-3} \mathrm{~cm}_{\mathrm{STP}}^{3} / \mathrm{g}\right)\end{array}$ & $\begin{array}{c}\Delta A^{c} \\
\left(10^{-3} \mathrm{~cm}_{\text {STP }}^{3} / \mathrm{g}\right)\end{array}$ \\
\hline Z01 & 15 & Degas & 0.7 & 0.1 & - & - \\
\hline Z02 & 15 & Degas & 0.4 & 0.2 & - & - \\
\hline Z03 & 40 & Degas & 1.1 & 0.3 & - & - \\
\hline Z04 & 40 & Degas & 1.9 & 0.5 & - & - \\
\hline Z05 & 40 & Degas & 1.7 & 0.4 & - & - \\
\hline Z06 & 80 & Degas & 0.8 & 0.2 & - & - \\
\hline Z07 & 100 & Air & - & - & 0.4 & 0.3 \\
\hline Z08 & 100 & Air & - & - & 0.0 & 0.3 \\
\hline Z09 & 100 & Air & - & - & 1.2 & 0.1 \\
\hline
\end{tabular}

${ }^{\mathrm{a}} \mathrm{Z}$, sediment depth.

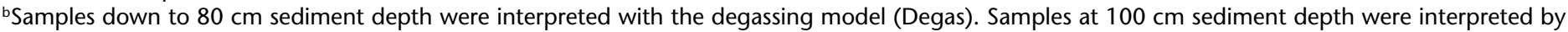
assuming a slight contamination of the sample with unfractionated air (Air).

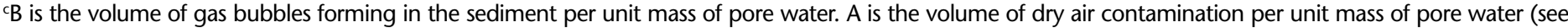
text). $B, A$, and the respective uncertainties $\Delta B$ and $\Delta A$ were estimated from the measured $\mathrm{Ne}, \mathrm{Ar}, \mathrm{Kr}$, and $\mathrm{Xe}$ data by least-squares regression.

Noble gas data from Lake Zug samples-The noble gas concentrations and isotope ratios observed in Lake Zug sediment are summarized in Table 1. As in the Küssnacht Basin, the He concentrations in the sediments of Lake Zug increase with sediment depth but with a lower degree of scatter. The $\mathrm{Ne}, \mathrm{Ar}, \mathrm{Kr}$, and Xe concentrations deviate substantially from the expected equilibrium concentrations, which will be discussed in the following paragraphs.

One sample (Z09) from $100 \mathrm{~cm}$ sediment depth shows a slight but distinct supersaturation with respect to Ne and Ar, whereas the $\mathrm{Kr}$ and $\mathrm{Xe}$ concentrations agree with the expected equilibrium concentrations. Because the solubilities of $\mathrm{Ne}$ and Ar are lower than those of $\mathrm{Kr}$ and $\mathrm{Xe}$, contamination with a small amount of air will cause a larger relative increase in the concentrations of $\mathrm{Ne}$ and $\mathrm{Ar}$ than in those of the heavier noble gases. Thus, contamination of the samples at $100 \mathrm{~cm}$ with air is likely. The sampling ports in the sediment liner were drilled after sediment coring, so that this contamination may have occurred then.

At $80 \mathrm{~cm}$ sediment depth and above, the $\mathrm{Ne}, \mathrm{Ar}, \mathrm{Kr}$, and $\mathrm{Xe}$ concentrations observed in the Lake Zug sediment porewater do not correspond to the expected atmospheric equilibrium concentrations. In general, the concentrations are lower than the atmospheric equilibrium concentrations at $4.4^{\circ} \mathrm{C}$ and 968.2 mbar atmospheric pressure (Table 1). This undersaturation is largest for Ne and decreases for the heavier noble gases. As shown in Fig. 6, the average of the Ne concentrations observed at $15 \mathrm{~cm}, 40 \mathrm{~cm}$, and $80 \mathrm{~cm}$ sediment depth is $8.3 \%$ lower than the expected equilibrium concentration, whereas the corresponding average Xe concentration is only $2.5 \%$ below the expected equilibrium concentration. The systematic decrease in noble gas depletion with gas solubility suggests that dissolved noble gases may have been removed by degassing into a reservoir free of noble gases. This degassing could have occurred either during the sampling process or naturally, in situ, before sampling. During sampling, small gas bubbles that had formed and been trapped in the sediment were observed to have been transferred into the sample containers together with the bulk sediment. Any noble gases that might have escaped from the porewater into these gas bubbles will therefore not have been lost during sampling. In addition, if degassing had occurred during sampling, the noble gas depletion would be expected to be highly variable even for replicate samples, which is not the case. Hence, we presume that the observed degassing depletion is not a sampling artifact but is a natural process which occurs in situ before sampling, as discussed below.

Under anoxic conditions, $\mathrm{CH}_{4}$ is produced in the sediment. This may cause the formation of $\mathrm{CH}_{4}$ gas bubbles. In this case, noble gases dissolved in the porewater partly escape into the

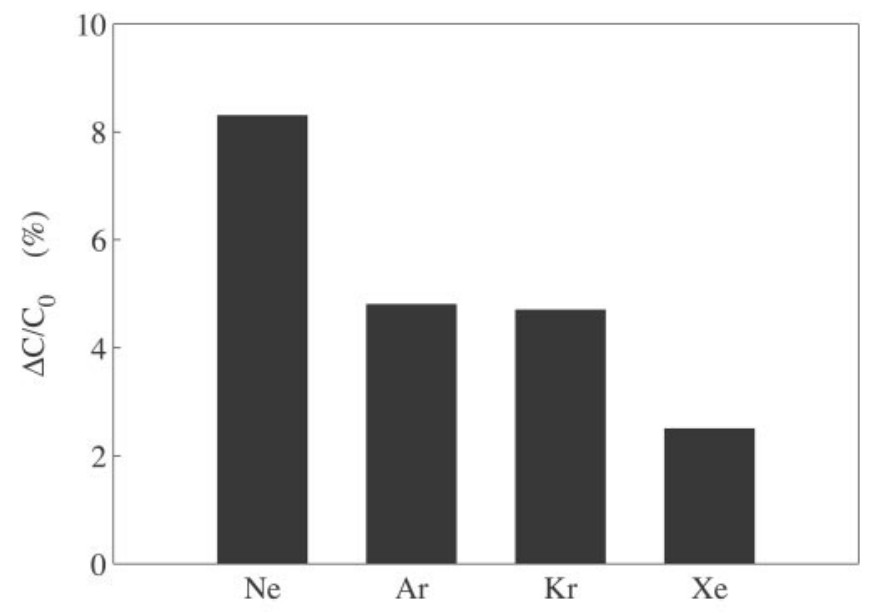

Fig. 6. Depletion of $\mathrm{Ne}, \mathrm{Ar}, \mathrm{Kr}$, and $\mathrm{Xe}$ because of degassing in the sediment of Lake Zug. $\Delta C$ is the difference between the expected noble gas equilibrium concentrations $C_{0}$ in the overlying water and the mean of the concentrations observed at $15 \mathrm{~cm}, 40 \mathrm{~cm}$, and $80 \mathrm{~cm}$ sediment depth. 
$\mathrm{CH}_{4}$ bubbles, which initially are free of noble gases. Re-equilibration of the dissolved noble gases with the gas bubbles occurs within a few minutes (Holocher et al. 2002, 2003). The gas bubbles will eventually ascend and leave the sediment, carrying the noble gases with them.

The gas composition in the porewater was modeled assuming an equilibration between porewater initially at atmospheric solubility equilibrium and gas bubbles that were initially free of noble gases. After equilibration, the noble gas concentration $\left(C_{i}\right)$ is given by:

$$
C_{i}=\frac{C_{i}^{*}}{1+B z_{i} / C_{i}^{*}} \quad i=\mathrm{Ne}, \mathrm{Ar}, \mathrm{Kr}, \mathrm{Xe}
$$

$C_{i}^{*}$ is the initial atmospheric equilibrium concentration. The term $z_{i} / C_{i}^{*}$ reflects the solubility of the noble gas $i$, where $z_{i}$ is the volume fraction of the respective noble gas in dry air. The degassing parameter $B$ is the STP volume of the gas bubble per unit mass of water after equilibration. The formulation of this model is analogous to the closed-system equilibration model of Aeschbach-Hertig et al. (2000), who use the parameters $A_{e}$ (initial STP volume of entrapped dry gas per unit mass of water) and $F$ (fractionation parameter), which we have combined here to yield our degassing parameter $B=A_{e} F$.

Table 4 summarizes the results of the degassing and air contamination models described above. The measured $\mathrm{Ne}, \mathrm{Ar}, \mathrm{Kr}$, and $\mathrm{Xe}$ concentrations were interpreted by applying the degassing model to the samples from $15 \mathrm{~cm}, 40 \mathrm{~cm}$, and $80 \mathrm{~cm}$ sediment depth. The $\mathrm{Ne}, \mathrm{Ar}, \mathrm{Kr}$, and Xe concentrations at 100 $\mathrm{cm}$ were modeled as equilibrium concentrations plus a small amount of unfractionated air $A$ (STP volume of air per unit mass of water). Parameter $B$ (15 to $80 \mathrm{~cm}$, degassing model) or $A(100 \mathrm{~cm}$, air contamination model) was determined from the $\mathrm{Ne}, \mathrm{Ar}, \mathrm{Kr}$, and Xe concentrations of each sample by leastsquares regression. A $\chi^{2}$ test was then applied to assess the applicability of the respective model. The sum of the squares of the deviation between the measured and modeled concentrations weighted by the measurement uncertainty $\left(\chi_{0}^{2}\right)$ follows a $\chi^{2}$ distribution. The probability $P$ that $\chi^{2}>\chi_{0}^{2}$ is a measure of the goodness of fit of the model. Here, $P$ was found always to exceed 0.05 , indicating excellent agreement of the modeled and measured data in all cases. Note that contamination with air is likely to be significant in only one sample $\left(Z 09, \sim 0.01 \mathrm{~cm}^{3}{ }_{\text {STP }}\right.$ dry air).

\section{Discussion}

Our new experimental method yields reproducible and interpretable noble gas concentrations in the porewater of lake sediments. Hence, the assessment of the noble gas record in the porewater as a paleolimnological archive carrying information about past physical conditions in a lake, e.g., temperature and salinity, has become feasible. The same techniques can, in principle, be applied in the ocean.
The comparison of sediment samples from deep-water and shallow-water regions of the Küssnacht Basin shows that the noble gas concentrations in the porewater reflect the different temperatures prevailing in the two regions. The difference in the noble gas concentrations is interpreted as the result of the two different surface water temperatures that govern gas exchange during the formation of deep and shallow lake water. In Lake Zug, the noble gas concentrations show a slight depletion-mainly in the case of the lighter noble gasesdown to $80 \mathrm{~cm}$ sediment depth, which can be interpreted by degassing into gas bubbles forming in the sediment. The noble gas concentrations in the lower sediment, which was deposited under aerobic conditions, do not show degassing depletion. This is consistent with the change in the oxic state of the Lake Zug sediment.

New data sets will reveal to what extent noble gas signals in the porewater are attenuated and smoothed by diffusion. It is expected that the signals of the heavier noble gases, which are also most sensitive to temperature and salinity changes, are least affected by diffusion, because the noble gas diffusivity decreases with mass. Based on this elemental fractionation, it may be possible to quantify the effective diffusivities of solutes in the porewater. Also, the analysis of the diffusive transport and in situ production of ${ }^{3} \mathrm{He}$ by the decay of ${ }^{3} \mathrm{H}$ may allow effective diffusion coefficients to be estimated. A detailed study of the diffusion of noble gases in the sediment porewater within the context of the use of noble gases as paleolimnological proxies will be published elsewhere.

Aside from diffusion, degassing into gas bubbles forming in biologically productive sediment may also result in reduced noble gas concentrations. This depletion is most pronounced in the case of the lighter, less soluble gases (Fig. 6). Thus, in "real-world" situations where the past noble gas concentrations in the overlying water are unknown, degassing can be detected by the undersaturation of Ne relative to Ar, $\mathrm{Kr}$, and $\mathrm{Xe}$ in the sediment. In extreme cases, preferential degassing of the lighter isotopes might even result in ${ }^{20} \mathrm{Ne} /{ }^{22} \mathrm{Ne}$ and ${ }^{36} \mathrm{Ar} /{ }^{40} \mathrm{Ar}$ ratios being lower than the atmospheric equilibrium values. The heavier noble gases are expected to carry most information about the past conditions of the overlying water because their solubility is more sensitive to temperature and salinity changes. At the same time, they are least affected by degassing. Hence, whereas Ne may show substantial depletion due to degassing, the heavier noble gases may still carry viable information about past water temperature and salinity. The atmospheric noble gas concentrations before degassing all reflect the same equilibration conditions. A comparison of the noble gas concentrations predicted by the degassing model with the measured concentrations thus allows not only the unknown degassing parameters to be estimated, but also the parameters describing the equilibrium conditions before degassing. Therefore, sediments affected by degassing may not necessarily be 
unsuitable for the reconstruction of past noble gas concentrations in the overlying water.

\section{Comments and recommendations}

Depending on the He release characteristics of the sediment matrix, the measured He generally consists of a mixture of dissolved He and trapped He released from the matrix. The release of trapped He may be minimized by decreasing the temperature at which the noble gases are extracted. At lower temperatures, however, either the blowout cannot be achieved or the extraction efficiency of the heavier noble gases may decrease to unacceptable levels. In these cases, peeper methods or the WSTP tool may be considered for the analysis of dissolved He. However, we advise cross-checking such data using analyses based on the method presented in this paper to rule out the sampling artifacts associated with these sampling devices. Furthermore, as He is poorly soluble it is easily stripped by the formation and migration of gas bubbles in the sediment. Therefore, the possible loss of He due to degassing should be assessed based on Ne-Xe measurements.

The sampling and extraction methods presented here might also have their uses for analyzing other dissolved gases, such as $\mathrm{Rn}$ or $\mathrm{CH}_{4}$. Especially when sampling volatile species, contact of the sample with air or other gas reservoirs must be avoided to prevent partial degassing or reequilibration of the sample. Our sampling technique allows rapid and routine sample preparation in the field. However, because chemically reactive species may be nonconservative during extraction at high temperatures, the extraction procedure may need to be adapted to the specific needs of the given species.

\section{References}

Aeschbach-Hertig, W., F. Peeters, U. Beyerle, and R. Kipfer. 1999. Interpretation of dissolved atmospheric noble gases in natural waters. Water Resour. Res. 35(9):2779-2792.

— , F. Peeters, U. Beyerle, and R. Kipfer. 2000. Palaeotemperature reconstruction from noble gases in ground water taking into account equilibration with entrapped air. Nature 405:1040-1044.

Barnes, R. 1973. An in situ interstitial water sampler for use in unconsolidated sediments. Deep-Sea Res. 20:1125-1128.

Barnes, R. O. 1979. Operation of the IPOD in situ pore water sampler, p 19-22. In J. Sibuet and W. Ryan, [eds.], Initial reports of the deep sea drilling project, vol. 47, part 2 . DSDP, Washington (U.S. Govt. Printing Office).

1988. ODP in-situ fluid sampling and measurement: a new wireline tool, $\mathrm{p}$ 55-63. In A. Mascle and J. Moore, [eds.], Proceedings of the ocean drilling program, initial reports (part A), vol. 110. ODP.

and R. H. Bieri. 1976. Helium flux through marine sediments of the Northern Pacific ocean. Earth Planet. Sci. Lett. 28:331-336.
Bayer, R., P. Schlosser, G. Bönisch, H. Rupp, F. Zaucker, and G. Zimmek. 1989. Performance and blank components of a mass spectrometric system for routine measurement of helium isotopes and tritium by the ${ }^{3} \mathrm{He}$ ingrowth method. Sitzungsberichte der Heidelberger Akademie der Wissenschaften Mathemathisch-naturwissenschaftliche Klasse 5, Springer-Verlag.

Beyerle, U., W. Aeschbach-Hertig, D. M. Imboden, H. Baur, T. Graf, and R. Kipfer. 2000. A mass spectrometric system for the analysis of noble gases and tritium from water samples. Environ. Sci. Technol. 34(10):2042-2050.

Dyck, W. and F. Da Silva. 1981. The use of ping-pong balls and latex tubing for sampling the helium content of lake sediments. J. Geochem. Explorat. 14:41-48.

Holocher, J., F. Peeters, W. Aeschbach-Hertig, M. Hofer, M. Brennwald, W. Kinzelbach, and R. Kipfer. 2002. Experimental investigations on the formation of excess air in quasisaturated porous media. Geochim. Cosmochim. Acta. 66(23):4103-4117.

—, F. Peeters, W. Aeschbach-Hertig, W. Kinzelbach, and R. Kipfer. 2003. Kinetic model of gas bubble dissolution in groundwater and its implications for the dissolved gas composition. Env. Sci. Technol. 37:1337-1343.

Kipfer, R. 1991. Primordiale Edelgase Als Tracer für Fluide aus dem Erdmantel. PhD thesis, ETH Zürich.

, W. Aeschbach-Hertig, F. Peeters, and M. Stute. 2002. Noble gases in lakes and ground waters, p. 615-700. In D. Porcelli, C. Ballentine, and R. Wieler, [eds.], Noble gases in geochemistry and cosmochemistry, vol. 47 of Rev. Mineral. Geochem. Mineralogical Society of America, Geochemical Society.

Livingstone, D. M. 1993. Temporal structure in the deep-water temperature of four swiss lakes: a short-term climatic change indicator? Verh. Internat. Verein. Limnol. 25:75-81.

Melles, M., M. Kulbe, P. Overduin, and S. Verkulich. 1994. Reports on polar research. Technical Report 148, AlfredWegner-Institut für Polar-und Meeresforschung.

Müller, B. 1993. Sauerstoffentwicklung im Zugersee. Master's thesis. ETH Zürich.

Peeters, F., and others. 2000. Analysis of deep-water exchange in the Caspian Sea based on environmental tracers. DeepSea Res. I 47(4):621-654.

Podosek, F. A., T. J. Bernatowicz, and F. E. Kramer. 1981. Adsorption of xenon and krypton on shales. Geochim. Cosmochim. Acta. 45:2401-2415.

Stephenson, M., W. J. Schwartz, T. W. Melnyk, and M. F. Motycka. 1994. Measurement of advective water velocity in lake sediment using natural helium gradients. J. Hydrol. 154:63-84.

Stute, M., and P. Schlosser. 2000. Atmospheric noble gases. p. 349-377 In P. Cook, and A. L. Herczeg, [eds.], Environmental tracers in subsurface hydrology. Kluwer Academic Publishers.

Tolstikhin, I. N., and R. K. O'Nions. 1994. The Earth's missing xenon: a combination of early degassing and of rare gas loss 
from the atmosphere. Chem. Geol. 115:1-6.

Torres, M., R. Bayer, G. Winckler, A. Suckow, and K. Froehlich. 1995. Elemental and isotopic abundance of noble gases in formation fluids recovered in situ from the Chile Triple Junction, p 321-329. In S. D. Lewis, J. H. Behrmann, R. J. Musgrave, S. C. Cande [eds.], Proceedings of the Ocean
Drilling Program, scientific results, vol. 141.

Winckler, G. 1998. Radiogenes Helium im Ozean: Drei Fallstudien. PhD thesis, Ruprecht-Karls-Universität Heidelberg.

Submitted 3 April 2003

Revised 8 July 2003

Accepted 22 September 2003 